\title{
Toughness and Microstructure of Coarse Grain Heat Affected Zone with High Heat Input Welding in Zr-bearing Low Carbon Steel
}

\author{
Minghao SHI, ${ }^{*}$ Pengyan ZHANG and Fuxian ZHU \\ State Key Laboratory of Rolling Technology and Automation, Northeastern University, Shenyang, 110819 China. \\ (Received on May 24, 2013; accepted on September 4, 2013)
}

\begin{abstract}
The microstructure and toughness of simulated coarse grained heat affected zone (CGHAZ) in low carbon steel have been investigated in this study. In order to simulate microstructure evolution in CGHAZ, specimens were subject to weld thermal cycle with heat input of $100 \mathrm{~kJ} / \mathrm{cm}, 400 \mathrm{~kJ} / \mathrm{cm}$ and $800 \mathrm{~kJ} / \mathrm{cm}$ at $1400^{\circ} \mathrm{C}$ peak temperature using thermal simulator. As increase in heat input energy of weld thermal cycle, prior austenite grain size increases due to longer holding time at peak temperature. Excellent impact toughness of CGHAZ with heat input of $800 \mathrm{~kJ} / \mathrm{cm}$ was obtained because of high volume fraction of fine acicular ferrite (AF) inside gain acting as an obstacle to cleavage propagation owe to its high angle grain boundary, forcing cleavage crack to change the route of propagation and effectively impedes the propagation of crack. The primary AF mainly originated from Zr-oxide particle with MnS and subsequently secondary AF nucleated sympathetically in form of side arms and grew from the primary AF in CGHAZ.
\end{abstract}

KEY WORDS: coarse grained heat affected zone (CGHAZ); acicular ferrite (AF); Zr-oxide; toughness; low carbon steel.

\section{Introduction}

In recent years, some high efficiency methods such as vertical electro gas arc welding (EGW) has been used in welding structure steels, where the welding heat input could range from 500 to $1000 \mathrm{~kJ} / \mathrm{cm}^{1)}$ and the steel near fusion line is heated to temperature of $1400^{\circ} \mathrm{C}$ or higher. High heat input thermal cycle can leads to significant austenite grain coarsening and some brittle microstructure form, such as upper bainite (UB) and ferrite side plate (FSP) growing into the grain at prior austenite boundaries, which is detrimental to toughness in coarse grained heat affected zone (CGHAZ). Therefore, there is great demand for steel in CGHAZ with good toughness after high heat input thermal cycle.

Micron-size second-phase particles promote intragranular nucleation of acicular ferrite (AF), and nano-size secondphase particles, such as $\mathrm{TiN}, \mathrm{Ti}_{2} \mathrm{O}_{3}, \mathrm{MnS}, \mathrm{ZrO}_{2}$ and $\mathrm{MgO}$, act as pinning particles during austenite grain growth and control of intragranular microstructure in CGHAZ. The addition of TiN to steels is widely used to improve toughness in CGHAZ through pinning austenite grain boundaries during welding thermal cycle. However, it is reported that dissolution of TiN particles at higher temperature $\left(1400^{\circ} \mathrm{C}\right)^{2)}$ may result in loss in grain refinement capability of TiN. Oxide metallurgy has a beneficial effect on the improvement of toughness in CGHAZ with high heat input welding thermal cycle because of high dissolution point and greater thermal stability.

Most research mainly focuses on the influence of Ti addi-

* Corresponding author: E-mail: minghao207@gmail.com

DOI: http://dx.doi.org/10.2355/isijinternational.54.188 tion on properties and microstructure of CGHAZ in low carbon steels. $\mathrm{Ti}_{2} \mathrm{O}_{3}$ was believed to be the most effective nucleation of intragranular ferrite in Ti-bearing low carbon steels. ${ }^{3-6)}$ Furthermore, some researchers reported that $\mathrm{MgO}$ particles were also most effective nucleation sites responsible for formation of $\mathrm{AF}$, and in inhibiting austenite grain growth in HAZ of low-carbon steels. ${ }^{7-9)}$ However, the relation of toughness and microstructure in CGHAZ with high heat input welding thermal cycle in Zr-bearing low-carbon steels is seldom studied. In this present study, specimens were subjected different high heat input welding thermal cycle to simulated microstructure transformation in CGHAZ, excellent impact toughness with high heat input was obtain in CGHAZ, especially heat input of $800 \mathrm{~kJ} / \mathrm{cm}$. We present results concerning the detailed sympathetic nucleation of secondary AF and effect of Zr-oxide particle on primary AF transformation in CGHAZ.

\section{Experimental Procedure}

\subsection{Specimen Preparation}

Experimental steel was refined by using a $25 \mathrm{~kg}$ vacuum induction melting furnace in laboratory. The chemical composition of steel is: $0.1 \mathrm{C}, 0.25 \mathrm{Si}, 1.4 \mathrm{Mn}, 0.005 \mathrm{~S}, 0.008$ $\mathrm{P}, 0.008 \mathrm{Zr}$ and $0.05 \geq(\mathrm{Nb}+\mathrm{Ti})($ wt.\%). The $100 \mathrm{~mm} \times 100$ $\mathrm{mm}$ ingot was reheated to $1200^{\circ} \mathrm{C}$ for $2 \mathrm{~h}$, and rolled into $16 \mathrm{~mm}$ plate by thermo-mechanical control processing (TMCP) in the recrystallized zone and the non-recrystallized zone with cooling rate of $15-20^{\circ} \mathrm{C} / \mathrm{s}$, final cooling temperature of $650^{\circ} \mathrm{C}$. And the as-rolled mechanical properties are as follows: yield strength $415 \mathrm{MPa}$, ultimate ten- 
sile strength $503 \mathrm{MPa}$, elongation $27 \%$ and average impact toughness $249 \mathrm{~J}\left(-20^{\circ} \mathrm{C}\right)$.

\subsection{High Heat Input Welding Thermal Cycle Proce- dure}

High heat input welding thermal cycle simulations were conducted on a thermo-mechanical simulator to study microstructure evolution and impact toughness changes in the CGHAZ. Simulated specimens were cut along the transversal direction of hot rolled steel plate and machined into dimensions $11 \mathrm{~mm} \times 11 \mathrm{~mm} \times 55 \mathrm{~mm}$ for CGHAZ simulations. High heat input welding thermal cycle was determined by the Rykalin mathematical heat transfer model to simulate the welding process. ${ }^{10)}$ The thermal cycle of the welding simulation is characterized by the peak temperature $\left(\mathrm{T}_{\mathrm{p}}\right)$, cooling time from $800^{\circ} \mathrm{C}$ to $500^{\circ} \mathrm{C}\left(\Delta t_{800-500}\right)$ and heat input energy (E). The high heat input welding thermal cycle parameter and curves is schematically shown in Fig. $\mathbf{1}$ and Table 1. The specimens were heated to peak temperature $\left(\mathrm{T}_{\mathrm{p}}\right)$ of $1400^{\circ} \mathrm{C}$ with heating rate of $100^{\circ} \mathrm{C} / \mathrm{s}$ and cooled at different cooling time for range of $800^{\circ} \mathrm{C}$ to $500^{\circ} \mathrm{C}$ to be equivalent to welding heat input of $100 \mathrm{~kJ} / \mathrm{cm}, 400 \mathrm{~kJ} / \mathrm{cm}$ and $800 \mathrm{~kJ} / \mathrm{cm}$.

\subsection{Impact Toughness Tests}

After CGHAZ simulation, the specimens were machined into standard Charpy-V-notch samples with dimensions 10 $\mathrm{mm} \times 10 \mathrm{~mm} \times 55 \mathrm{~mm}$ and then subjected to impact tests at $-20^{\circ} \mathrm{C}$ on an Instron Dynatup 9200 series instrumented drop weight impact tester.

\subsection{Metallographic Observations}

The metallographic observation region was fixed near the monitoring thermocouple and then polished using standard metallographic procedures and etched with 3 vol $\%$ Nital in order to reduce the error resulting from relatively uneven cooling rate. And prior austenite grain size was measured

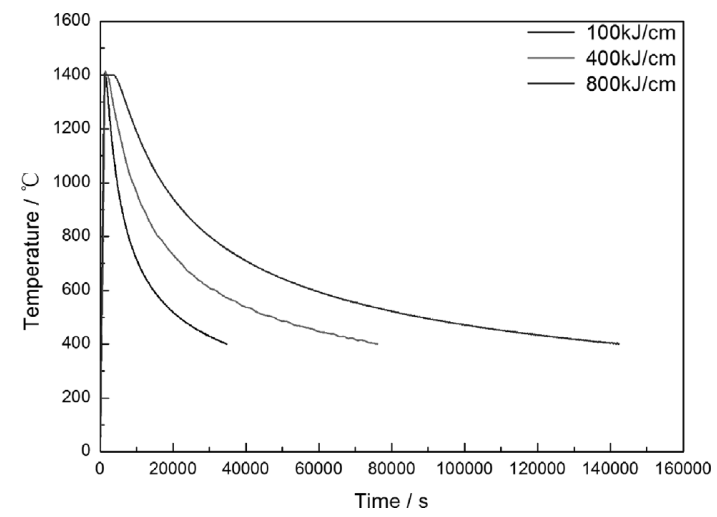

Fig. 1. Schematic diagram of welding thermal cycle.

Table 1. Parameter of high heat input welding thermal cycle.

\begin{tabular}{cccc}
\hline $\begin{array}{c}\text { Peak Temp. } \\
\left({ }^{\circ} \mathrm{C}\right)\end{array}$ & $\begin{array}{c}\text { Holding Time at } \\
\text { Peak Temp. }(\mathrm{sec})\end{array}$ & $\begin{array}{c}\Delta t_{800-500} \\
(\mathrm{sec})\end{array}$ & $\begin{array}{c}\text { Heat Input } \\
(\mathrm{kJ} / \mathrm{cm})\end{array}$ \\
\hline 1400 & 1 & 137.5 & 100 \\
1400 & 3 & 214 & 400 \\
1400 & 30 & 730 & 800 \\
\hline
\end{tabular}

with the line intercept method based on low magnification OM. The microstructures of CGHAZ were examined using optical microscopes (OM), scanning electron microscopy (SEM) equipped with an energy dispersive X-ray spectroscopy (EDX) analysis and transmission electron microscopy (TEM).

\section{Results}

\subsection{Austenite Grain Size of CGHAZ}

Figure 2 shows relationship between prior austenite grain size and heat input. Prior austenite grain size increases with heat input increasing because of longer holding time at $1400^{\circ} \mathrm{C}$ peak temperature as shown in Table 1 .

\subsection{Charpy Impact Toughness of CGHAZ}

Figure 3 shows charpy impact toughness of CGHAZ tested at $-20^{\circ} \mathrm{C}$ after different high heat input welding thermal cycle. It is very interesting that average impact toughness of CGHAZ after heat input of $100 \mathrm{~kJ} / \mathrm{cm}$ (average $299 \mathrm{~J}$ ) and $400 \mathrm{~kJ} / \mathrm{cm}$ (average $346 \mathrm{~J}$ ) are larger than base metal (average $249 \mathrm{~J}$ ). Further increase of heat input to $800 \mathrm{~kJ} / \mathrm{cm}$ resulted in decrease in impact toughness (average $223 \mathrm{~J}$ ), lower than base metal.

\subsection{Microstructure of Base Metal and CGHAZ}

Figure 4 shows the microstructures of base metal and CGHAZ at different heat input. Microstructures of base metal are composed of ferrite and pearlite. High volume fraction of AF inside grain and small block of grain bound-

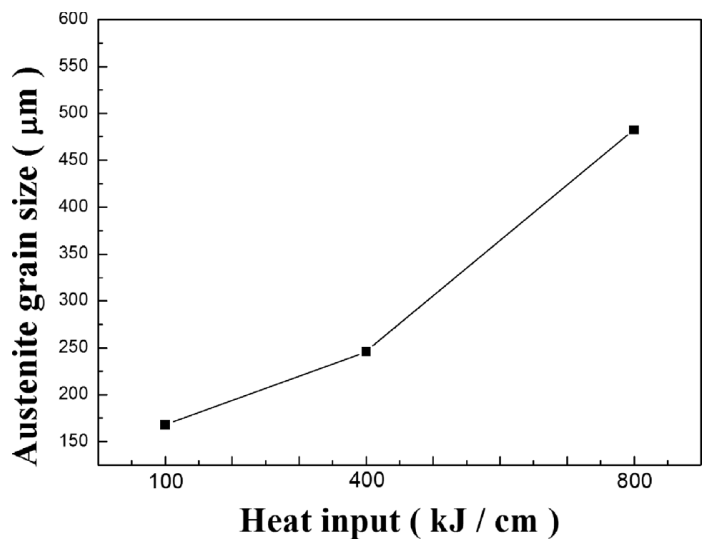

Fig. 2. Austenite grain size after different heat input.

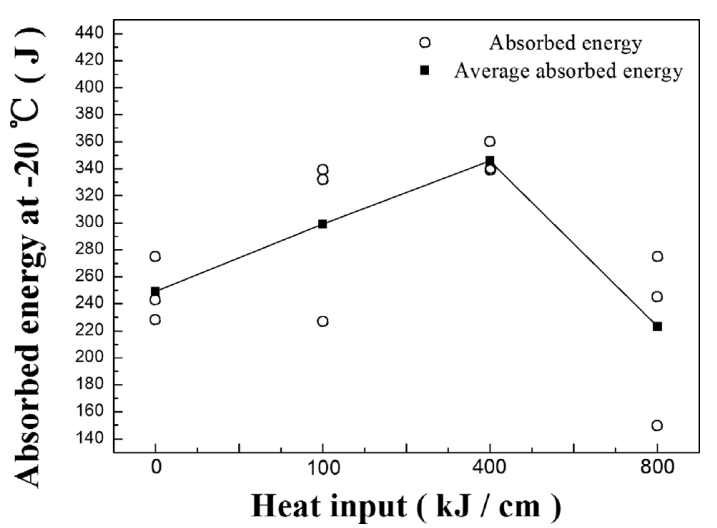

Fig. 3. Charpy impact toughness of CGHAZ at different heat input. 


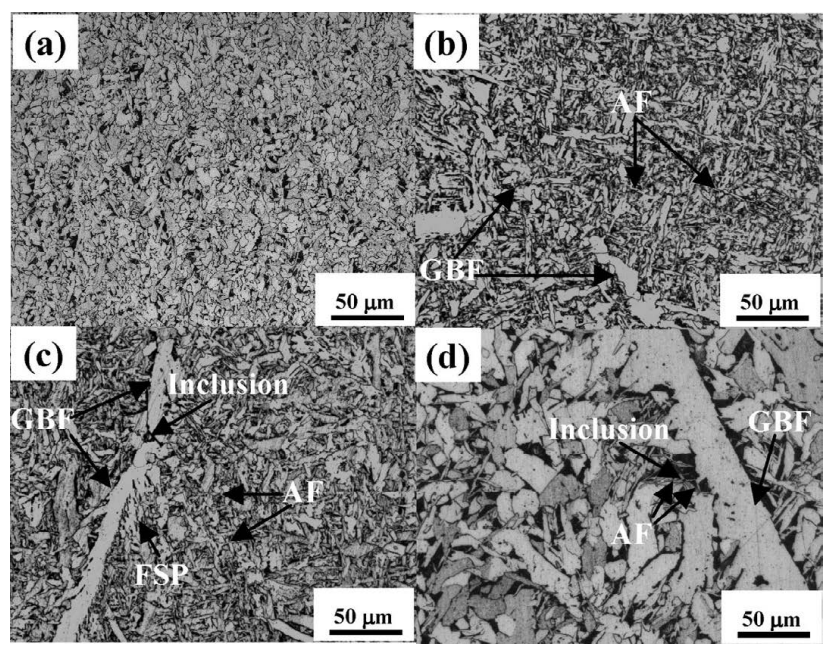

Fig. 4. Microstructure of base metal and CGHAZ at different heat input.

aries ferrite $(\mathrm{GBF})$ at prior austenite grain boundary are observed in the specimen with $100 \mathrm{~kJ} / \mathrm{cm}$. Further increase of heat input, FSP at austenite grain boundary growing into grain presents in the specimen with $400 \mathrm{~kJ} / \mathrm{cm}$. Large block of GBF formed at prior austenite grain boundary in the specimen with $800 \mathrm{~kJ} / \mathrm{cm}$ because of long time cooling from $800^{\circ} \mathrm{C}$ to $500^{\circ} \mathrm{C}$. It is important to note that the formation of fine AF near austenite grain boundary prevents FSP transformation as shown in the specimen with $800 \mathrm{~kJ} / \mathrm{cm}$, resulting in the improvement of toughness at CGHAZ.

\section{Discussion}

\subsection{Effect of Heat Input Energy on Toughness at CGHAZ}

It is found that toughness of base metal is lower than CGHAZ except heat input of $800 \mathrm{~kJ} / \mathrm{cm}$. The variation of impact toughness in CGHAZ can be explained by the amount of AF inside the prior austenite grains and formation of GBF at austenite grain boundary. A coarser austenite grain size to reduce grain boundary surface area may then be required in order to shift the balance of ferrite nucleation from the austenite grain boundaries to the intragranular regions (assuming inclusions are inert substrates) because of long holding time at peak temperature, so that high volume fraction of AF are kinetically favourable. The observation is consistent with the conclusions proposed by $\mathrm{T}$. Koseki and G. Thewlis. ${ }^{11)}$ It is known that GBF transformation occurs at high temperature when specimens cooling from $800^{\circ} \mathrm{C}$ to $500^{\circ} \mathrm{C}$, and the transformation energy barrier is low at prior austenite grain boundaries. Therefore, large block of GBF appear in the specimen with $800 \mathrm{~kJ} / \mathrm{cm}$ because of long cooling time from $800^{\circ} \mathrm{C}$ to $500^{\circ} \mathrm{C}$ leading to deterioration of toughness, as shown in Fig. 4.

Figure 5 shows crack paths in the specimen with $400 \mathrm{~kJ} /$ $\mathrm{cm}$ and $800 \mathrm{~kJ} / \mathrm{cm}$. Fine interlocking AF and its disordered lath arrangement acts as an obstacle to cleavage propagation because of its high angle grain boundary, forcing cleavage crack to change the route of propagation and effectively impedes the propagation of crack. And large block of GBF provides path for crack cleavage resulting in decreasing toughness of CGHAZ.
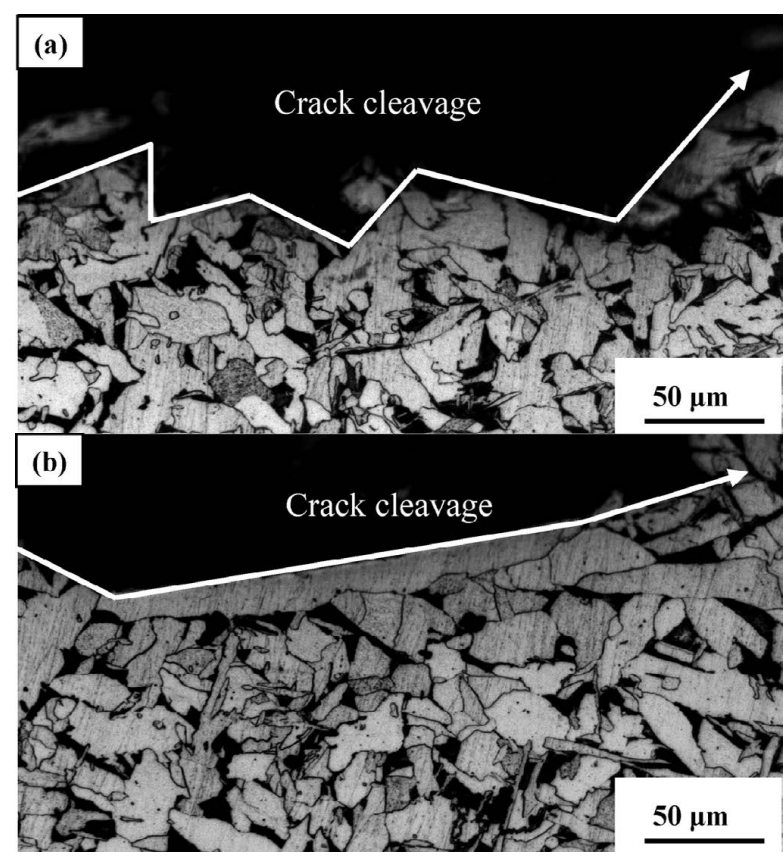

Fig. 5. Optical micrographs showing morphologies of crack paths in specimen with $400 \mathrm{~kJ} / \mathrm{cm}$ and $800 \mathrm{~kJ} / \mathrm{cm}$.

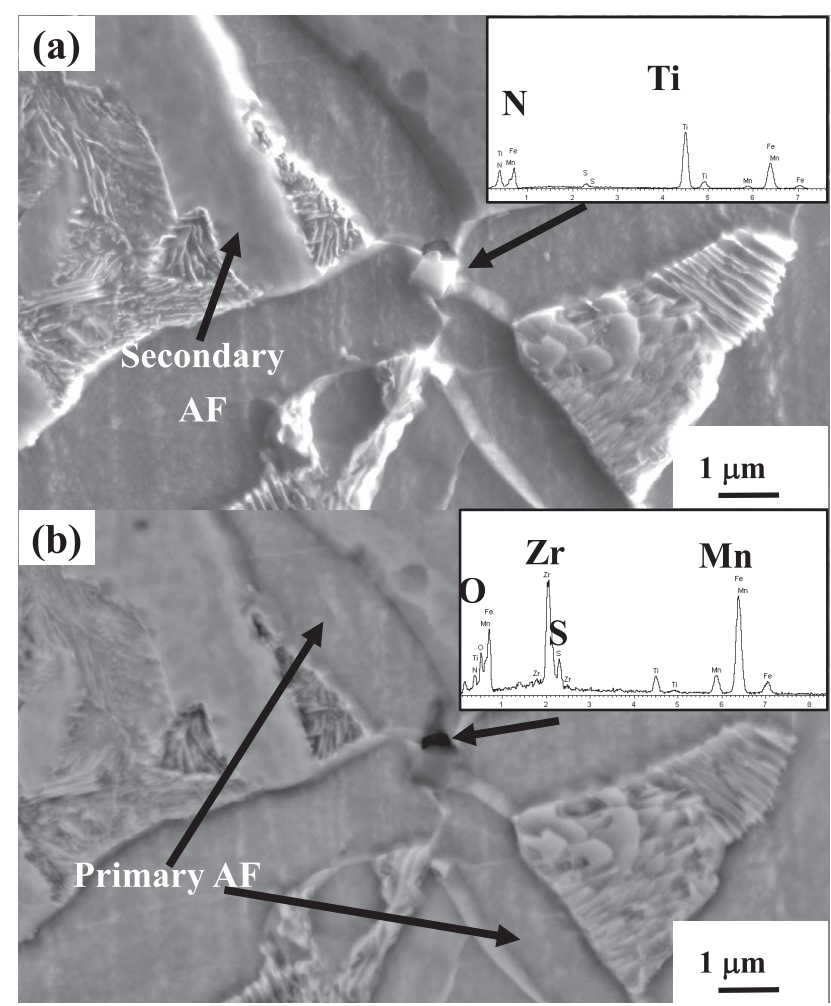

Fig. 6. Precipitation of TiN on surface of oxide particle at CGHAZ in specimen with $800 \mathrm{~kJ} / \mathrm{cm}$, (a) secondary electron image and (b) backscatter image.

\subsection{Effect of TiN on Acicular Ferrite Transformation}

Figure 6 shows micrograph showing precipitation of TiN on the surface of $\mathrm{Zr}$-oxide particle with $\mathrm{MnS}$ at CGHAZ in the specimen with $800 \mathrm{~kJ} / \mathrm{cm}$. Figure 7 shows AF nucleating on $\mathrm{Zr}$-oxide particle with $\mathrm{MnS}$, which do not consist of $\mathrm{TiN}$, and precipitation of TiN alone on surface of ferrite, in the specimen with $800 \mathrm{~kJ} / \mathrm{cm}$. It is notable that precipitation of TiN alone on surface of ferrite was not observed in the 

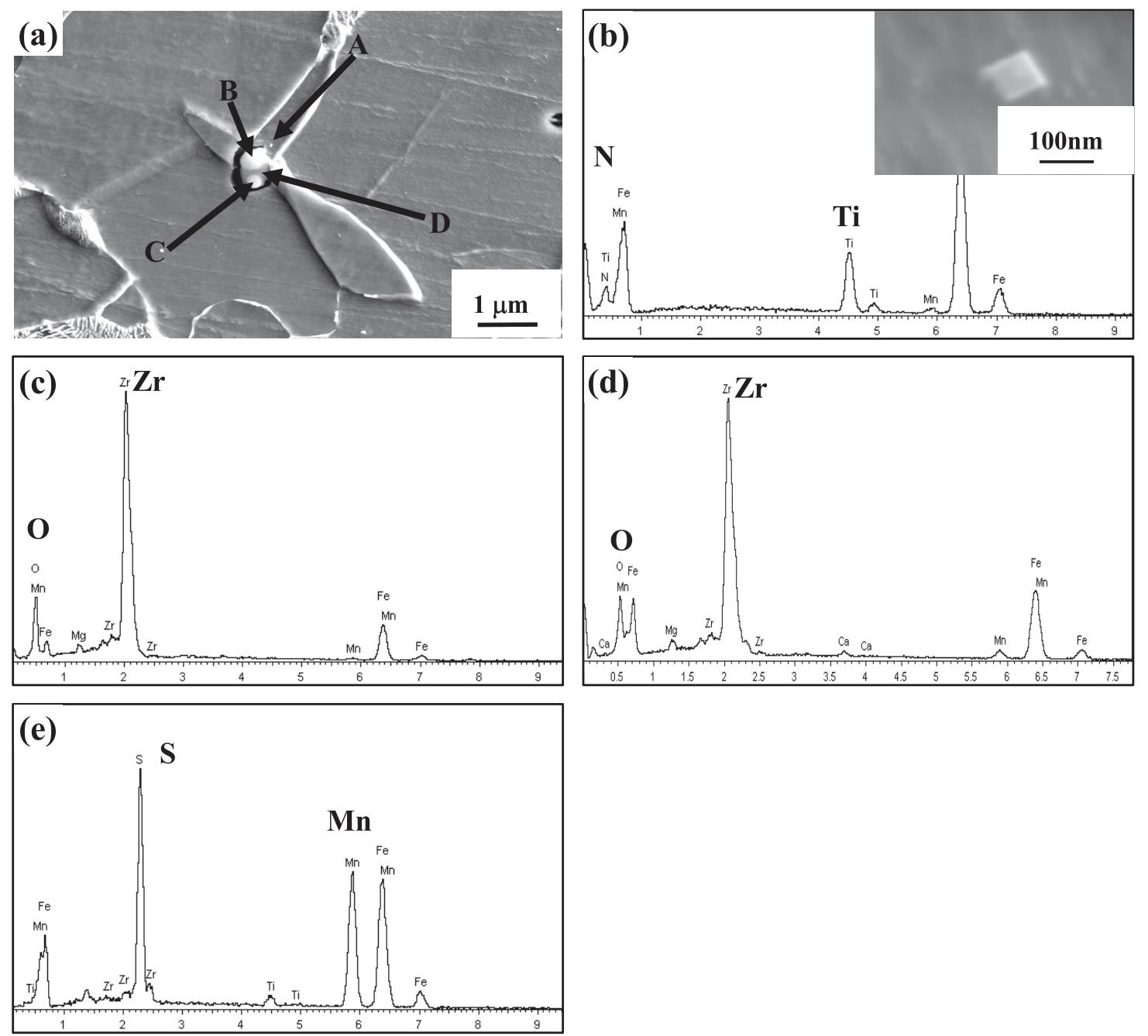

Fig. 7. Precipitation of small TiN and oxide particle assisted nucleation of AF at CGHAZ in specimen with $800 \mathrm{~kJ} / \mathrm{cm}(\mathrm{a})$, EDS spectrum of precipitate (b), location A (c) and location B (d).

other specimen with $100 \mathrm{~kJ} / \mathrm{cm}$ and $400 \mathrm{~kJ} / \mathrm{cm}$. TiN particle tend to dissolve during the thermal cycle along with $\mathrm{MnS}$. During cooling, oxide particle may act as substrates for reprecipitation of TiN and $\mathrm{MnS}$ phases taken into solution on heating, because oxide particle are stable during thermal cycle at high temperature. ${ }^{3)}$ Re-precipitation of TiN at CGHAZ is kinetically favourable during heat input of 800 $\mathrm{kJ} / \mathrm{cm}$ thermal cycle due to long cooling time.

Bramfitt ${ }^{12)}$ suggested that the mis-match strain between inclusion and ferrite or austenite should be low for nucleation to occur. The value of lattice disregistry was very small for TiN (3.9\%) base on the calculation by Bramfitt. However, the Zr-oxide particle with $\mathrm{MnS}$ assisted nucleation of AF and small TiN did not act as the nucleation site of AF at CGHAZ in this study, as shown in Fig. 7. It is inferred that the lattice matching is not the dominant requirement for nucleation of $\mathrm{AF}$, and there is increasingly strong evidence for chemical reaction or depletion idea, such as depletion of Mn content near oxide particle. ${ }^{4)}$ This result support the conclusion obtained by Gregg and Bhadeshia ${ }^{13}$ in steel inoculation experiments.

\subsection{Effect of Sympathetic Nucleation on Impact Toughness of CGHAZ}

It is found that the number of AF occurring in such col- onies, which is defied as secondary $\mathrm{AF}$, is greater than the number of AF nucleating on inclusion. Barbaro et al. ${ }^{14)}$ have reported that the number of AF was an order of magnitude greater than the number of inclusions. Therefore, other intragranular nucleation mode may be operative in addition to nucleation on inclusions. Primary AF is nucleated by inclusions and secondary AF grows from the primary AF or nucleates intragranularly at other sites as shown in Fig. 6. The present work supports the suggestion proposed by Ricks et al. ${ }^{15)}$ secondary AF develop from the primary AF nucleated on inclusions. Formation of primary AF on inclusions creates a large increase in surface of 'new phase boundaries', which provide excellent sites for further sympathetic nucleation and growth of secondary AF. The primary $\mathrm{AF}$ initially originated from $\mathrm{Zr}$-oxide particle with $\mathrm{MnS}$ and subsequently secondary AF nucleated on the surface of 'new phase boundaries' in form of side arms nucleating sympathetically and grew from the primary AF. High super cooling may drives secondary nucleation, and at the same time increases dislocation density of the transformed products. High volume fraction of dislocations was observed between primary AF and secondary AF in Fig. 8. It could be assumed that the dislocations acted as channel for carbon diffusion, and the 'new phase boundaries' formed at the surface of primary AF nucleating on inclusions. 


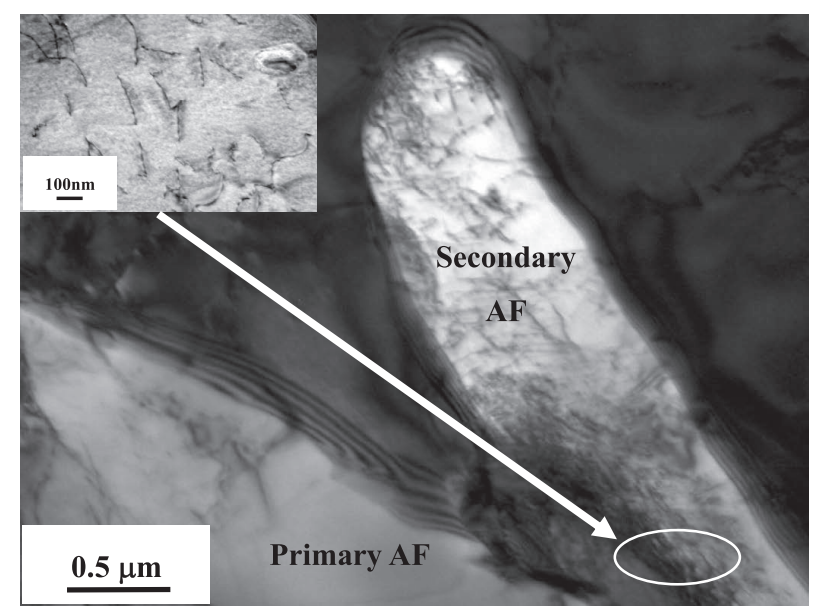

Fig. 8. TEM micrograph of secondary AF growing from primary AF.

\section{Conclusions}

(1) Excellent impact toughness of CGHAZ with high heat input welding thermal cycle was obtained in this study, because of high volume fraction of AF at CGHAZ. Average absorbed energy of specimen with heat input of $800 \mathrm{~kJ} / \mathrm{cm}$ tested at $-20^{\circ} \mathrm{C}$ is $233 \mathrm{~J}$.

(2) Large block of GBF presented at prior austenite grain boundaries in the specimen with $800 \mathrm{~kJ} / \mathrm{cm}$, which provided path for crack cleavage resulting in decreasing toughness of CGHAZ. Austenite grain size increased with heat input increasing because of different holding time at peak temperature.

(3) Zr-oxide particle with $\mathrm{MnS}$ assisted nucleation of AF at CGHAZ in this study. The lattice matching is not the dominant requirement for nucleation of acicular ferrite, and solute element depleted zone, especially Mn-depleted zone,
(MDZ), adjacent to the oxide inclusions in the austenite matrix may be primary reasons for inclusion assisted nucleation of AF.

(4) Dislocations in primary AF acted as channel for carbon diffusion, and the formation of 'new phase boundaries' at the surface of primary AF provided nucleation sites for secondary AF. The formation of AF occurs in two stages. Primary AF form by intragranular nucleation on inclusions and further growth then occurs in the form of side arms nucleating sympathetically and growing from the primary AF.

\section{Acknowledgements}

The present study is supported by the National Natural Science Foundation of China through grant number: 50834019.

\section{REFERENCES}

1) K. Y. A. Kojima, T. Hada, O. Saeki, K. Ichikawa, Y. Yoshida, Y. Shimura and K. Azuma: Nippon Steel Tech Rep., 380 (2004), 33.

2) F. Chai, C. Yang, H. Su, Y. Zhang, Z. Xu and Y. Yang: Acta Metall. Sin. (English Letters), 21 (2008), 220.

3) K. Yamamoto, T. Hasegawa and J.-I. Takamura: ISIJ Int., 36 (1996), 80 .

4) H. Mabuchi, R. Uemori and M. Fujioka: ISIJ Int., 36 (1996), 1406

5) J.-L. Lee and Y.-T. Pan: ISIJ Int., 35 (1995), 1027.

6) Z. Zhang and R. Farrar: Mater. Sci. Technol., 12 (1996), 237.

7 V. Trindade, R. Mello, J. Payao and R. Paranhos: J. Mater. Eng. Per., 15 (2006), 284.

8) A. Kojima, A. Kiyose, R. Uemori, M. Minagawa, M. Hoshino, T. Nakashima, K. Ishida and H. Yasui: Nippon Steel Tech Rep., 90 (2004), 2 .

9) M. Nagahara and H. Fukami: Nippon Steel Tech Rep., 90 (2004), 9.

10) N. Rykalin: Caculation of Heat Processes in Welding, Mashgiz, Moscow, USSR, (1960), 4.

11) T. Koseki and G. Thewlis: Mater. Sci. Technol., 21 (2005), 867.

12) B. L. Bramfitt: Metall. Mater. Trans. B, 1 (1970), 1987.

13) J. Gregg and H. Bhadeshia: Acta Mater., 45 (1997), 739.

14) F. Barbaro, P. Krauklis and K. Easterling: Mater. Sci. Technol., 5 (1989), 1057.

15) R. Ricks, P. Howell and G. Barritte: J. Mater. Sci., 17 (1982), 732. 